\title{
EFFECT OF TEMPERAMENT ON CORTISOL RESPONSE TO A SINGLE EXERCISE BOUT IN THOROUGHBRED RACEHORSES - SHORT COMMUNICATION
}

\author{
Zsófia BoHÁK ${ }^{1}$, Ottó SzENCI ${ }^{1}$, Andrea HARNOS ${ }^{2}$, Orsolya KUTASI ${ }^{1}$ and Levente KovÁCS ${ }^{1,3^{*}}$ \\ ${ }^{1}$ MTA-SZIE Large Animal Clinical Research Group, Üllő, Dóra major, H-2225 Hungary; \\ ${ }^{2}$ Department of Biomathematics and Informatics, University of Veterinary Medicine, \\ Budapest, Hungary; ${ }^{3}$ Institute of Animal Husbandry, Faculty of Agricultural and \\ Environmental Science, Szent István University, Gödöllö, Hungary
}

(Received 1 April 2017; accepted 6 November 2017)

\begin{abstract}
Temperament has not been taken into account in previous studies evaluating the stress response to exercise in horses. The aim of the present study was to investigate the cortisol response in Thoroughbred racehorses to a single exercise bout, and to analyse the results based on the basic personality of the horse examined. Twenty healthy Thoroughbred horses were selected for the study based on a 25 -item rating questionnaire survey used for characterising equine temperament. Eight temperamental and twelve calm horses took part in the experiment. The horses trotted as a warm-up activity, and then galloped on a rounded sand track. Blood sampling was conducted four times for each horse. Horses with a more excitable temperament showed a higher cortisol response to the test $(\mathrm{P}=0.036)$. In conclusion, cortisol levels in response to a mild intensive exercise can be affected by temperament in horses. Serum cortisol may be a relevant marker to quantify individual temperamental differences in racehorses.
\end{abstract}

Key words: Stress, equine, cortisol response, exercise, blood plasma

Temperament has major importance in handling ease and performance of horses (Lansade and Simon, 2010; Christensen et al., 2012). It describes the relatively stable differences in the behavioural predisposition of animals, which can be related to psychobiological mechanisms (Manteca and Deag, 1993; Zuckerman, 2005). Stress is one of the main triggers of the hypothalamic-pituitaryadrenocortical (HPA) axis, and therefore it is often assessed by the determination of cortisol concentrations. Exercise may induce an intensive stress reaction (Graaf-Roelfsema et al., 2007), and cortisol response to exercise has been reported in equine studies (Gordon et al., 2007; Petruse et al., 2015). Several studies

*Corresponding author; E-mail: Kovacs.Levente@mkk.szie.hu; Phone: 0036 (30) 944-3990

This is an open-access article distributed under the terms of the Creative Commons Attribution License, which permits unrestricted use, distribution, and reproduction in any medium for non-commercial purposes, provided the original author and source are credited. 
BOHÁK et al.

have examined horses on treadmills (Malinowski et al., 2006; Gordon et al., 2007); however, this abnormal type of work might influence stress response even in accustomed horses (Sloet van Oldruitenborgh-Oosterbaan and Clayton, 1999).

Exercise-induced increase in plasma cortisol concentrations was found to be linearly related to work intensity in horses by Church et al. (1987), however, in another experiment plasma cortisol concentrations did not show an increase concomitant with treadmill velocity (Nagata et al., 1999) in Thoroughbred racehorses. It has been demonstrated that the duration of exercise is a more relevant trigger for the exercise-induced cortisol increase than the intensity of physical activity (GraafRoelfsema et al., 2007). It is thus questionable whether discrepancies between these studies are due to the lack of standards in experimental designs using exercise as stressor, or individual-related factors are responsible for the variability of results. Although several studies have shown that HPA activity and responses to usual stressors can differ with temperament in production animals (Curley et al., 2008; Pajor et al., 2013; Kovács et al., 2016), it is still unclear whether cortisol level could be influenced by temperament in horses. Therefore, the aim of this study was to bring researchers one step closer to answering the question whether cortisol response in Thoroughbred horses to a single exercise bout differs with temperament. We hypothesised that horses with a more excitable temperament will show higher cortisol response to the exercise than calmer horses.

All procedures involving animals were approved by the Ethics Committee of the Faculty of Veterinary Science, Szent István University. From 27 healthy horses, 20 healthy Thoroughbred stallions $(\mathrm{n}=10)$ and mares $(\mathrm{n}=10)$, aged three years, were selected for the study based on a 25 -item rating questionnaire survey used for characterising equine temperament on a 7-point scale (Lloyd et al., 2007). The traits 'excitability' and 'anxiousness' were used in this study. Scores given for both trait components were summarised, then averaged. Based on the questionnaire, horses were classified as 'calm' (scores $0-2$; means $\pm \mathrm{SD}=1.2 \pm 0.3$ ), 'average' (scores 3-4; means $\pm \mathrm{SD}=3.4 \pm 0.2$ ) and 'temperamental' (scores 5-7; means $\pm \mathrm{SD}=5.2 \pm 0.3)$. Average horses $(\mathrm{n}=7)$ were excluded. Eight temperamental (five stallions and three mares) and 12 calm horses (five stallions and seven mares) took part in the experiment.

Prior to the study, the horses were trained five days a week for three months. Horses were kept in $3 \times 3 \mathrm{~m}$ commercial boxes and maintained on a diet of hay and concentrated feedstuff, such as oat and mash. Water was provided ad libitum. The experimental period was fit in the daily training schedule. The same trainer that answered the questionnaire had dealt with all the horses since the first mounting of a rider.

Data were collected between 10 and 25 June, daily between 05:00 and 07:00 a.m., ensuring that the temperature remained between $18-23^{\circ} \mathrm{C}$ during the test. Horses were equipped with a Polar Equine RS800CX Multi device and GPS (Polar Ltd., New York, USA) for recording their heart rate, distance travelled, 
and velocity. Horses had a 10-min warm-up trot with a rider, and then galloped $2,300 \mathrm{~m}$ on a rounded sand track. To avoid the psychical influence of rider instructions, horses were allowed to gallop without restraint or encouragement. In all cases, the rider was the familiar jockey of the horse. All of the horses galloped alone during the test.

Blood was collected by jugular venipuncture into heparinised tubes (SMonovette, Sarstedt, Nümbrecht-Rommelsdorf, Germany) during the following periods: in the morning at rest between 05:00 and 06:00 a.m. (S0), after the warmup period (S1), after the galloping period (S2), and after the 30-min recovery period (S3). Samples were cooled to and stored at $4{ }^{\circ} \mathrm{C}$ until centrifugation at $2000 \mathrm{~g}$ for $10 \mathrm{~min}$. Plasma was removed and stored at $-18^{\circ} \mathrm{C}$ until cortisol assay. Cortisol analyses were performed in duplicates using a direct RIA method validated for horses (Peeters et al., 2011) with a high-performance liquid chromatographer (HPLC) preparation of cortisol-3-corticosterone methyloxidase, coupled with 2$\left[{ }^{125} \mathrm{I}\right]$ iodohistamine as a tracer for specific antibodies raised against cortisol-3CMO-BSA. Briefly, the lower detection limits of the assays were $8 \mathrm{nmol} / \mathrm{L}$. The CVs for between-run assays were $<11.3 \%$ and the intra-assay CVs were $<5.6 \%$.

The analyses were carried out using the R 3.2.3 statistical software (R Core Team R, 2012). For hypothesis testing, a linear mixed model was fitted. Cortisol level was the response, while horse type (calm or nervous) and the sampling time (S0, S1, S2, or S3) and their interactions were the explanatory variables. The dependence between measurements from the same individual (horse) was taken into account by modelling the within-horse error variance-covariance matrix. The linear mixed model was fitted using the Restricted Maximum Likelihood method, 'nmle' package (Pinheiro and Bates, 2000). Model effects were tested together based on their $t$-values. For multiple comparisons, we tested contrast and applied the Tukey method to avoid the accumulation of Type 1 errors.

To avoid the psychical influence of rider instructions, horses were allowed to run without restraint during the gallop phase of the training, i.e. velocity was not influenced by the rider; therefore, the intensity of the exercise was not completely standardised. However, when focusing on performance results, it turns out that the horses performed workouts of similar strength. The GPS-recorded average and maximum velocity, as well as the average and maximum heart rate of the horses did not differ statistically between groups $(\mathrm{P}=0.17$ and $\mathrm{P}=0.49$; $\mathrm{P}=0.16$ and $\mathrm{P}=0.22$, respectively).

A distinct increase in serum cortisol concentrations was observed in both temperamental and calm horses in response to the exercise (Fig. 1). An exerciseinduced increase in plasma cortisol concentrations of approximately $25-30 \%$ has previously been reported in horses (Church et al., 1987; Martinez et al., 1988; Gordon et al., 2007). In our study, the maximal cortisol levels were $105.1 \pm$ $15.3 \mathrm{nmol} / \mathrm{L}$ and $119.9 \pm 16.9 \mathrm{nmol} / \mathrm{L}$, which were $22.6 \pm 3.3 \%$ and $43.1 \pm 6.0 \%$ higher than baseline levels in calm and temperamental horses, respectively. 


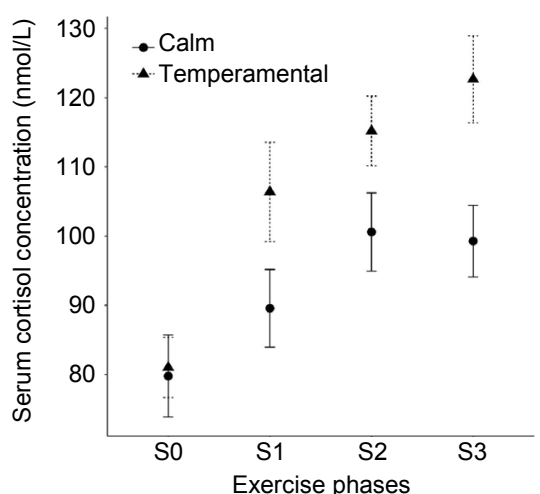

Fig. 1. Serum cortisol levels of calm $(\mathrm{n}=12)$ and temperamental $(\mathrm{n}=8)$ horses in response to exercise (means $\pm \mathrm{SEM}$ ). S0 = baseline, $\mathrm{S} 1=$ after warming up, $\mathrm{S} 2=$ after gallop, $\mathrm{S} 3$ = after a 30-min recovery

In line with a recent observation in cattle (Kovács et al., 2016), we found no difference in basal serum cortisol concentrations ( $\mathrm{S} 0)$ between temperament groups $(\mathrm{P}=0.888)$, reflecting that human presence prior to the exercise did not cause higher stress for temperamental horses than for calm ones. Although it was non-significant, the difference between groups was already visible at the S1 and $\mathrm{S} 2$ samplings $(\mathrm{P}=0.084$ and $\mathrm{P}=0.141$, respectively), while 30 min after the gallop phase (S3) cortisol levels were significantly higher for temperamental than for calm horses $(\mathrm{P}=0.036)$.

The effect of temperament on changes in cortisol in response to exercise has not been reported in horses so far. Exercise means not only physiological stress for horses. Horses are also exposed to environmental, social, and psychological factors during the daily training. Based on our results, responsiveness to these effects may affect the strength of the cortisol response.

We demonstrated that cortisol levels could be affected by temperament in response to a mild intensive exercise in horses. Serum cortisol seems to be a relevant marker to quantify individual differences in racehorses. The analysis of HPA axis reactivity may be fundamental for a better understanding of the physiological aspects of temperament in horses and it might be necessary to consider behavioural traits in future physiological studies on racehorses.

\section{Acknowledgements}

The authors thank Gábor Csepi, DVM, for his assistance with this work. We are grateful to Bábolna National Stud Farm for supplying the horses. Dr. Levente Kovács was supported by the János Bolyai Research Scholarship of the Hungarian Academy of Sciences and the Postdoctoral Scholarship of the National Research, Development and Innovation Office (project no. PD123456). 


\section{References}

Christensen, J. W., Ahrendt, L. P., Lintrup, R., Gaillard, C., Palme, R. and Malmkvist, J. (2012): Does learning performance in horses relate to fearfulness, baseline stress hormone, and social rank? Appl. Anim. Behav. Sci. 140, 44-52.

Church, D. B., Evans, D. L., Lewis, D. R. and Rose, R. J. (1987): The effect of exercise on plasma adrenocorticotrophin, cortisol and insulin in the horse and adaptations with training. In: Gillespie, J. R. and Robinson, N. E. (eds) Equine Exercise Physiology 2. ICEEP Publications, Davis, CA. pp. 506-515.

Curley, Jr. K. O., Neuendorff, D. A., Lewis, A. W., Cleere, J. J., Welsh, T. H. and Randel, R. D. (2008): Functional characteristics of the bovine hypothalamic-pituitary-adrenal axis vary with temperament. Horm. Behav. 53, 20-27.

Gordon, M. E., McKeever, K. H., Betros, C. L. and Manso Filho, H. C. (2007): Exercise induced alterations in plasma concentrations of ghrelin, adiponectin, leptin, glucose, insulin, and cortisol in horses. Vet. J. 173, 532-540.

Graaf-Roelfsema, E. H., Keizer, A., Van Breda, E., Wijnberg, I. D. and van der Kolk, J. H. (2007): Hormonal responses to acute exercise, training and overtraining - a review with emphasis on the horse. Vet. Quart. 29, 82-101.

Kovács, L., Kézér, F. L., Kulcsár-Huszenicza, M., Ruff, F., Szenci, O. and Jurkovich, V. (2016): Hypothalamic-pituitary-adrenal and cardiac autonomic responses to transrectal examination differ with behavioral reactivity in dairy cows. J. Dairy Sci. 99, 7444-7457.

Lansade, L. and Simon, F. (2010): Horses' learning performances are under the influence of several temperamental dimensions. Appl. Anim. Behav. Sci. 125, 30-37.

Lloyd, A. S., Martin, J. E., Bornett-Gauci, H. L. I. and Wilkinson, R. G. (2007): Evaluation of a novel method of horse personality assessment: Rater-agreement and links to behaviour. Appl. Anim. Behav. Sci. 105, 205-222.

Malinowski, K., Shock, E. J., Rochelle, P., Kearns, C. F., Guirnalda, P. D. and McKeever, K. H. (2006): Plasma $\beta$-endorphin, cortisol and immune responses to acute exercise are altered by age and exercise training in horses. Equine Vet. J. Suppl. 36, 267-273.

Manteca, X. and Deag, J. M. (1993): Individual differences in temperament of domestic animals: A review of methodology. Anim. Welf. 2, 247-268.

Martinez, R., Godoy, A., Naretto, E. and White, A. (1988): Neuroendocrine changes produced by competition stress on the Thoroughbred race horse. Comp. Biochem. Physiol. A Comp. Physiol. 91, 599-602.

Nagata, S., Takeda, F., Kurosava, M., Mima, K., Hiragat, A., Kait, M. and Taya, K. (1999): Plasma adrenocorticotropin, cortisol and catecholamines response to various exercises. Equine Vet. J. Suppl. 30, 570-574.

Pajor, F., Kovács, A., Tőzsér, J. and Póti, P. (2013): The influence of temperament on cortisol concentration and metabolic profile in Tsigai lambs. Arch. Tierzucht 56, 573-580.

Peeters, M., Sulon, J., Beckers, J. F., Ledoux, D. and Vandenheede, M. (2011): Comparison between blood serum and salivary cortisol concentrations in horses using an adrenocorticotropic hormone challenge. Equine Vet. J. 43, 487-493.

Petruse, C., Chirila, A. B., Mot, T. and Morar, D. (2015): Dynamic of plasma cortisol in response to physical training in Thoroughbred horses. J. Biotechnol. Suppl. 208, 92-93.

Pinheiro, J. C. and Bates, D. M. (2000): Mixed-Effects Models in S and S-PLUS. Springer.

R Core Team R (2012): A Language and Environment for Statistical Computing. R Foundation for Statistical Computing, Vienna, Austria. ISBN 3-900051-07-0, URL http://www.R-project.org/.

Sloet van Oldruitenborgh-Oosterbaan, M. and Clayton, H. M. (1999): Advantages and disadvantages of track vs. treadmill tests. Equine Vet. J. Suppl. 30, 645-647.

Zuckerman, M. (2005): Psychobiology of Personality. Second edition. Cambridge University Press, Cambridge. 